Original Research Paper

\title{
A System for Item Analysis Examination on Cloud Computing Service
}

\author{
Kriangsak Chanthinok and Palan Jantarajaturapath \\ Department of Digital Business and Information System, \\ Mahasarakham Business School (MBS), Mahasarakham University, Thailand
}

Article history

Received: 06-04-2020

Revised: 26-05-2020

Accepted: 20-06-2020

Corresponding Author:

Kriangsak Chanthinok

Department of Digital Business and Information System,

Mahasarakham Business

School (MBS), Mahasarakham

University, Thailand

Email: kriangsak.c@acc.msu.ac.th

\begin{abstract}
Item Analysis Examination (IAE) system is an electronic online instructional tool that can be openly accessible on the cloud computing service. This IAE system has been developed with PHP language with CSS bootstrap and MySQL database. Six months after launching the website, Perceived Usefulness, Perceived Ease of Use, User's Satisfaction and Attribute of Use of the IAE system were assessed. The online questionnaire was also collected on the website and the result affirmed that the system was a promising tool with high effectiveness to be used in educational institutes. Additionally, the mean score of the user's satisfaction was surprisingly higher than 3.50. At this point, the mean score of gender difference, between male and female, was statistically significant in the IAE system for all aspects. There was none of the statistical significance found in the difference between the educational and audient type proportion. Moreover, our study provides the exam analysis to optimize the best items for future usage and the IAE system has been firmly tested to be a high-quality tool to measure and assess the student's knowledge in a digital era.
\end{abstract}

Keywords: Item Analysis Examination, Cloud Computing, Difficulty Index Analysis

\section{Introduction}

The examination system is a very important mechanism in an educational area since it helps evaluate levels of student's knowledge and performance in the classroom. Even though an online exam currently allows teachers to easily and quickly create question items for the test, the testing system development is still manual in which all the questions and answers need to be managed manually (Nuthong et al., 2019). In addition, the learner's quality depends on not only good courses, suitable teaching and learning approaches, but also on the quality of testing equipment that represents an exam academic achievement and the quality of teaching and learning approaches.

However, the best quality of the examination is based on the difficulty and sophistication index which is the key point to achieve the university's educational standard. Therefore, the improvement of item analysis examination is required in order to perform the more effective testing approach in the next period (Sungnul et al., 2011). Typically, the performance of the item analysis examination system is considerably based on its difficulty index and classification power index (e.g., an ability to differentiate the talented and the weak groups).
Generally, most examination software in the market have some restriction such as slow answer-check, the required installation before using the system on computers, etc. The solutions to this restriction may vary depending on each institute education. Currently, the web application technology can spontaneously serve and respond to many users within the same period. The web application also can be available on a remote server and delivered via the Internet through a web browser openly accessible on any of the operation system. Hence, these web applications need none of the installations since they are freely accessible through a network. Users can reach a web application through several web browsers such as Google Chrome, Mozilla Firefox or Safari as they are accessible via various platforms such as a desktop, laptop, or mobile device. Particularly in terms of the web server using the cloud computing service, the cloud software will provide specific and already-created applications running with cloud infrastructure (Höfer and Karagiannis, 2011). From the above mentioned, this research aimed to implement the cloud computing service for the item analysis examination management. In this regard, the researcher came up with an idea of developing a web application for multiple-choice 
examination analysis in order to improve the examination quality as well as to provide a free service to teachers in educational institutions around Thailand. Therefore, the objectives of this research are (1) To develop the difficulty index analysis software for multiple-choice examination via cloud computing service; and (2) To assess the IAE system's Perceived Usefulness, Perceived Ease of Use, User's Satisfaction and Attribute of Use.

The paper was organized with several sections including section 2: Literature Review and Relative Works; section 3: An Overview of IAE System; section 4: Materials and Method; section 5: Discussion and Results; and section 6: Conclusion.

\section{Literature Review and Relative Work}

The web-based examination system is an effective solution for mass educational evaluation as previously mentioned in the study by Zhenming et al. (2003) on developing a novel online examination system based on a browser/server framework to carry out the examination and auto-grading system for objective questions and question items management with different software e.g., Microsoft Windows, Microsoft Word, Excel and PowerPoint, etc. Their study outcome has been successfully applied to the distant evaluation of basic operating skills of computer science; for example, the computer skill courses in universities and the nationwide examination for the high school graduates in Zhejiang Province, China.

Moreover, the mobile agent-based online examination system and the roles of mobile agents were applied to the system. This system was initially developed by Aye and Thwin (2008) in order to provide the infrastructure for conducting the computer-based examination in which the candidates may be spread over in large areas. Their system actually aimed to map the real-world examination system with the concentration on the full stage of the examination from the question setting to the answer evaluation. This mobile agent-based system practically provided several advantages including scalability, flexible structuring, dynamic extensibility, push-pull modes of information dissemination, evaluation of subjective question and transparency to varying communication channels, application-layer multicasting, network latencies and dynamic content delivery.

According to the research works in Thailand, the web application development for item analysis for the objective test had been discussed by Chinnasri and Wasukree (2016) whose research objectives were: (1) to develop the web application for item analysis, (2) to evaluate the performance of the web application for item analysis and (3) to evaluate the user's satisfaction on the web application for item analysis. Their developed web application consisted of two main parts: Part 1 - the exam result file check; and Part 2 - the exam result file analysis using PHP language programming and its performance was evaluated by 5 experts. The web application's overall performance for item analysis was rated with a very high score (Mean $(\bar{x})=4.87$, Standard Deviation (S.D.) $=0.221$ ) as the user's satisfaction evaluated by 23 teacher candidates after trying out the web applications for item analysis and their overall usage -satisfaction was showed at a very high level $(\bar{x}=$ 4.87, S.D. = 0.237). Considering each item, it was found that the analysis result can be imported and saved as a Microsoft Excel file from this web application and the web application worked smoothly on the computer with no need to install additional software. After all, the user's satisfaction was evaluated and resulted at a very high level $(\bar{x}=4.96$, S.D. $=0.209)$.

Bhoomin Ton-Oud (2017) previously studied the development of multiple-choice answer sheet checking systems by an image processing method to develop the multiple-choice test checking systems using an imageprocessing software and to examine the efficiency of the multiple-choice answer sheet at the Faculty of Science and Technology in Kamphaeng Phet Rajabhat University. The researcher developed the software with an image-processing method together with a K-Means clustering method and the software could be run by order controlling and actively contracting with the user by order controlling and contacting with a user while it was receiving the answer image and the answer sheet from students at the same time. The images were later processed through an automatic document feeder scanner to be analyzed and the scores were summarized in a form of the report. Additionally, the efficiency test of the answer sheet analysis was classified into 3 parts. The first part was the test to verify the result of the answer sheet analysis in which five cases were considered as follows: "Crossing only one choice, "Crossing more than one choice", "No crossing at all", "Crossing only one choice with correction liquid"- Erased the wrong choice" and "Crossing only one choice with a line-crossed wrong choice". The percentages of the verified values of each case were: 100, 99.60, 100, 99.50 and $97.10 \%$, respectively. The second part was the speed test of the answer sheet analysis indicating that the average processing speed was at 11.5 seconds per one page without scanning times. Finally, the percentages of the application test were $100 \%$. The results of the test were found that the answer sheet of the students with the correctly-crossed choices was the one with only one crossed-choice with no erased choices on a line and no line-crossed wrong choice. So, this kind of answer sheet could be analyzed to provide the $100 \%$ correct score. 
In addition, Nuthong et al. (2019) studied the automatic quiz generation mechanism for multiplechoice question by applying an ontological data and recommended that the quiz generation system is very important in education since it helps assess students' understanding of the lesson as well as allows users to easily and quickly create the test. However, the current quiz generation system still has a limitation in creating the questions; this was also faced by the user themselves. In fact, it takes longer to create a set of test so their research aimed to create the automatic quiz generation mechanism for multiple-choice questions by applying ontological information to assess the difficulty level of the questions. The hybrid similarity was measured using a combination of semantic similarity, semantic relatedness and property values to determine the difficulty level of the question. On this matter, the proposed mechanism was implemented using the RDFaCE tool and PHP program to create an interface for the user to input and display the results of the quiz creation based on the user-defined data. In addition, the proposed mechanism was firmly validated to provide accurate performance. By comparison, the difficulty score was derived from the proposed mechanism and the item response theory as the evaluation results were consistent by $80 \%$. Therefore, the proposed automatic quiz generation mechanism was an applicable tool to quickly and easily create quizzes and reduce the working time on creating an increasing number of multiple-choice questions which could be varied. Also, this mechanism was able to accurately determine the difficulty level of the questions as required.

However, the aforementioned indicated that although the examination system has been developed for both online and offline platforms, it is still incapable of integrating the infrastructure with the cloud computing service and it has not been broadly applied in the educational institutions. Therefore, this research was aiming at fulfilling this gap for the item analysis examination system with the cloud computing service.

\section{A System for Item Analysis Examination: An Overview}

The IAE system development is the service for all lecturers and students regarding educational purposes. The researcher also used PHP language and MySQL as a database to store the registered members and other necessary data e.g., exam questions, section data, pre-test and post-test management. Exactly this database openly allows the lecturers with their owner's account to add new, edit and delete the data by themselves. Moreover, all data would be privately displayed on the website only visible for the registered teachers. Also, the students can view only the exam assigned by the teacher in each class. Especially, this IAE system was composed of several features as follows:
1. The member can use the system via all smart devices e.g., mobile phones, tablets, desktop computers and portable computers

2. Teachers can export student's scores into the excel files to be processed together with other scores before grade calculation

3. Teachers can detect incorrect answers then analyze and improve them

4. The same exam can be assigned and defined as either pre-test or post-test

5. the examination has no limitation since it allows users to take the exams in a variety of subjects with plenty of times

6. It is a tool for teachers to improve their student's learning efficiency starting from the elementary level to the tertiary level throughout Thailand

7. It motivates students to be alert and excited about their learning because the test results will be announced immediately so they can compare their scores with classmates

8. This IAE can be freely signed up at www.mseexam.net

\section{Cloud Computing Service}

The could computing service provides 3 service platforms: Software as a Service (SaaS), Platform as a Service (PaaS) and Infrastructure as a Service (IaaS). Indeed, the IAE service is considered a SaaS type, which is a similar service provided by Gmail, Google Docs or Google Apps since it is a form of using software through a web browser. The audience is able to use documents, calculate and create data presentations with no need to install any software on the hardware and it can be used on any device and anywhere (Bhardwaj et al., 2010) (Fig. 2). Several benefits of cloud computing service are illustrated below:

- Cloud technology is paid incrementally so it is cost saving for organizations

- An organization can store more data on private computer systems

- The IT staffs need not to worry about updating the software

- Cloud computing service offers much more flexibility than previous computing methods

- Less worry about constant server updates and other computing issues, government organizations will be free to concentrate on innovation.

- The flexibility to choose a number of service providers with reliable and scalable business services, development environments and infrastructure that can be leveraged out of the box and billed on a metered basis-with no long-term contracts 
- The elastic nature of the service infrastructure that can be rapidly allocated and de-allocated the massively scalable resources to business services on a demand basis

- It is cost-saving due to the operational efficiencies and more rapid deployment of new business services

\section{The Proposed System for Item Analysis Examination Website}

It is the website that aims to serve in the Thai education system and to replace the paper-based examination. Practically, a teacher can import the question items and analyze the student's learning growth record as well as retracing the student's score history. Consequently, this website will be easy for a teacher to teach and guide the students to a correct solution. Basically, the proposed IAE system needs to define types of access. Namely, if the user is a student, he/she can log in with the username/password given by the teacher in the classroom. When his log-in was complete, the examination will be displayed on the private area of the website. In fact, all students are allowed only to take the exam and view the score report from the previous part.

However, if the user is the teacher, they can import all students' data into the classroom at once. After importing, the teachers can manage the exam type, create the exam or update questions, as well as importing all the exams. Moreover, the teachers can define the exam time and classify the difficulty index from the examination analysis on each item after finishing the exam. Yet, the system allows the teachers to export the scores from each exam into the spreadsheet file for the customized analysis.

In terms of the system's functionality as Teacher Actor, a teacher has to login to the system as a Teacher as shown in Fig. 1.

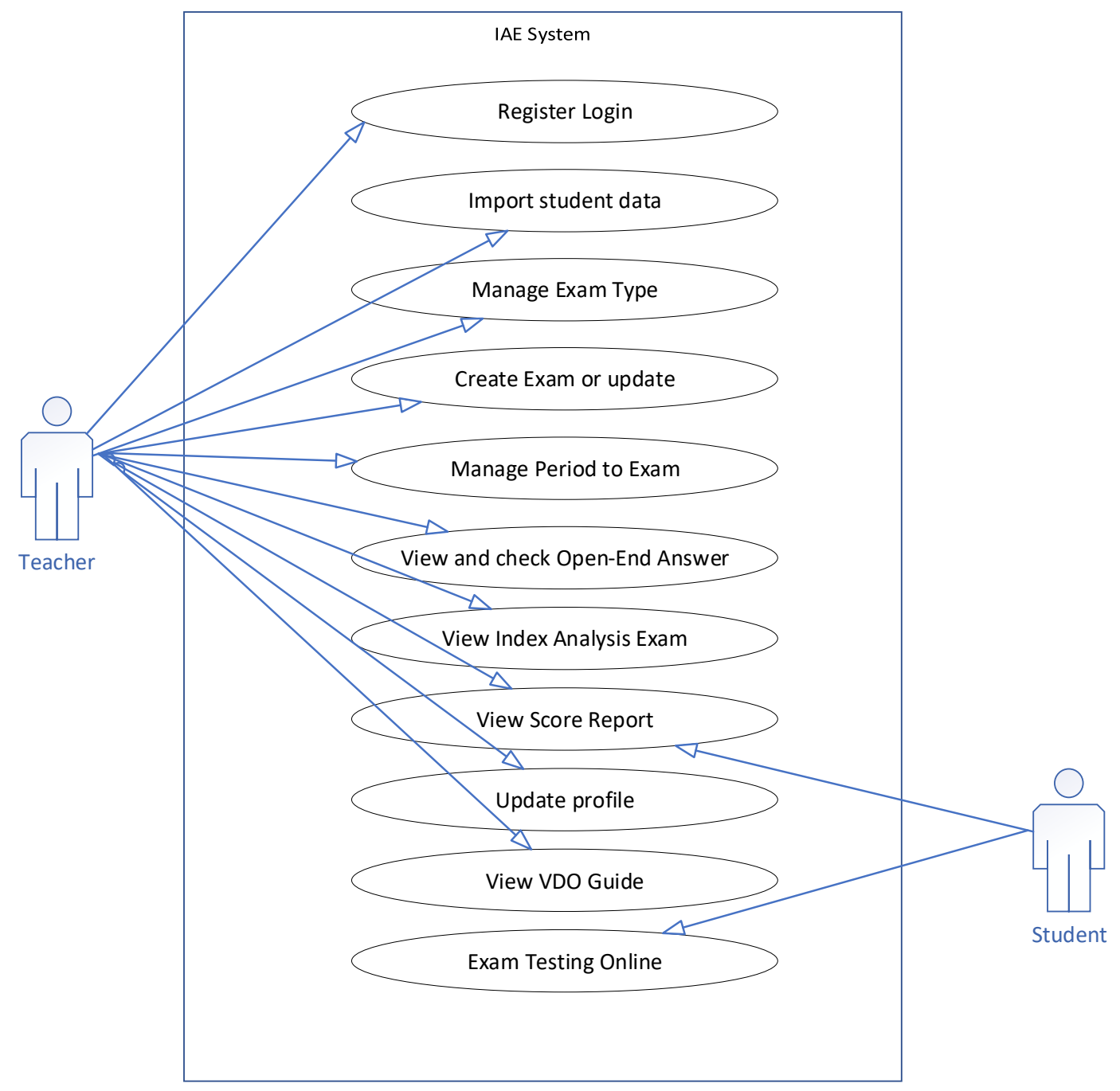

Fig. 1: Functionality of IAE system 


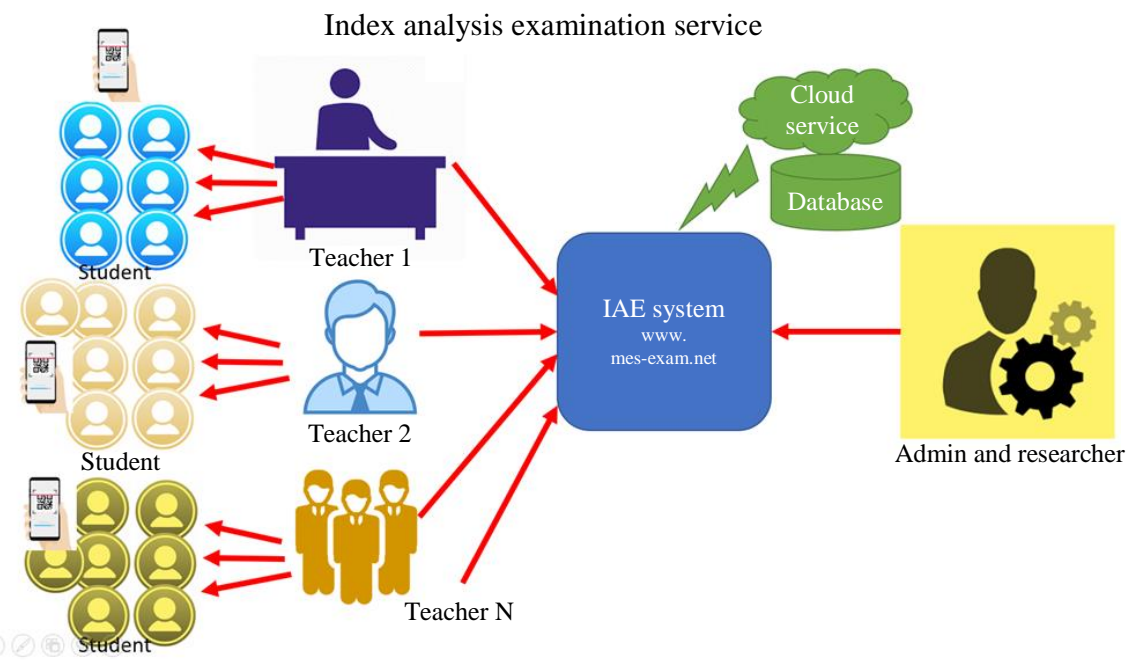

Fig. 2: The principle of IAE system on cloud computing service (Bhardwaj et al., 2010)

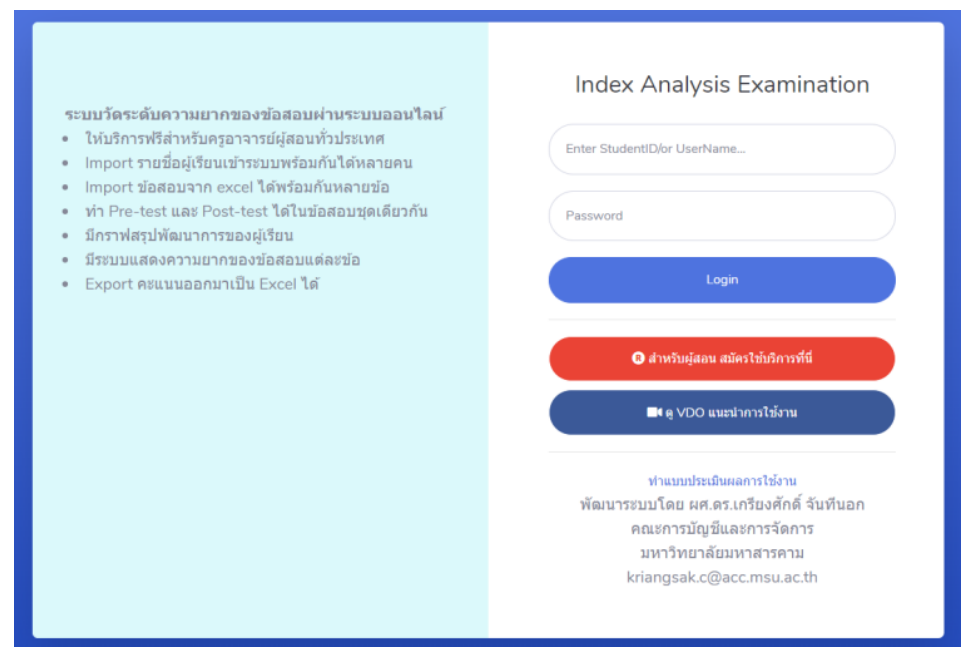

Fig. 3: The snapshot of login page (https://www.mse-exam.net)

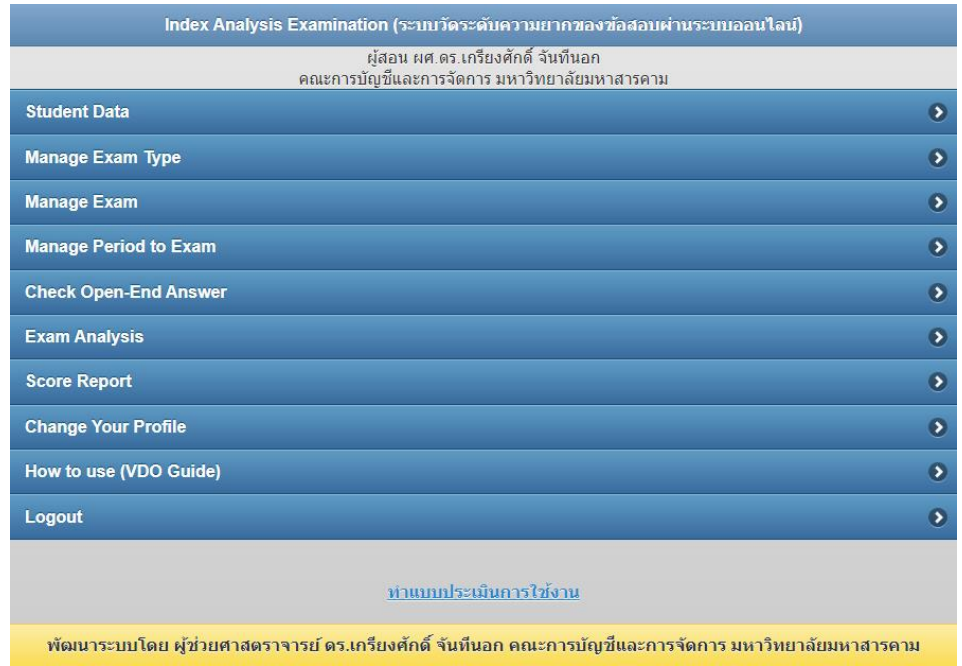

Fig. 4: The snapshot of administrator menu (https://www.mse-exam.net/menu.php) 


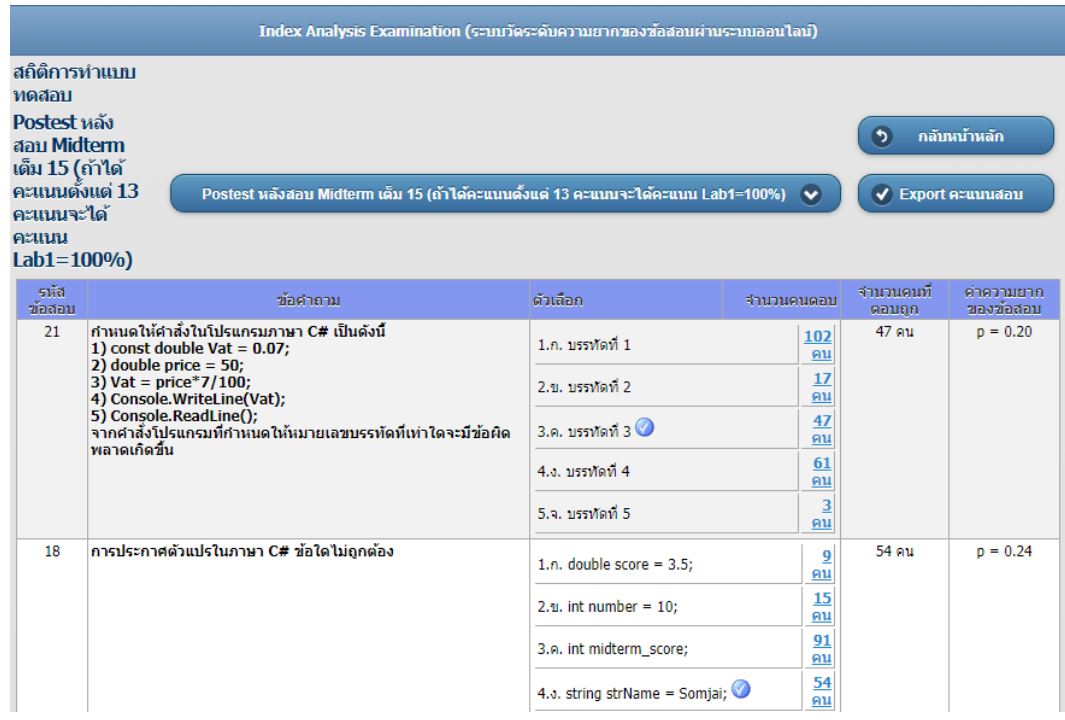

Fig. 5: The snapshot of item analysis page (https://www.mse-exam.net/exam_analysis.php)

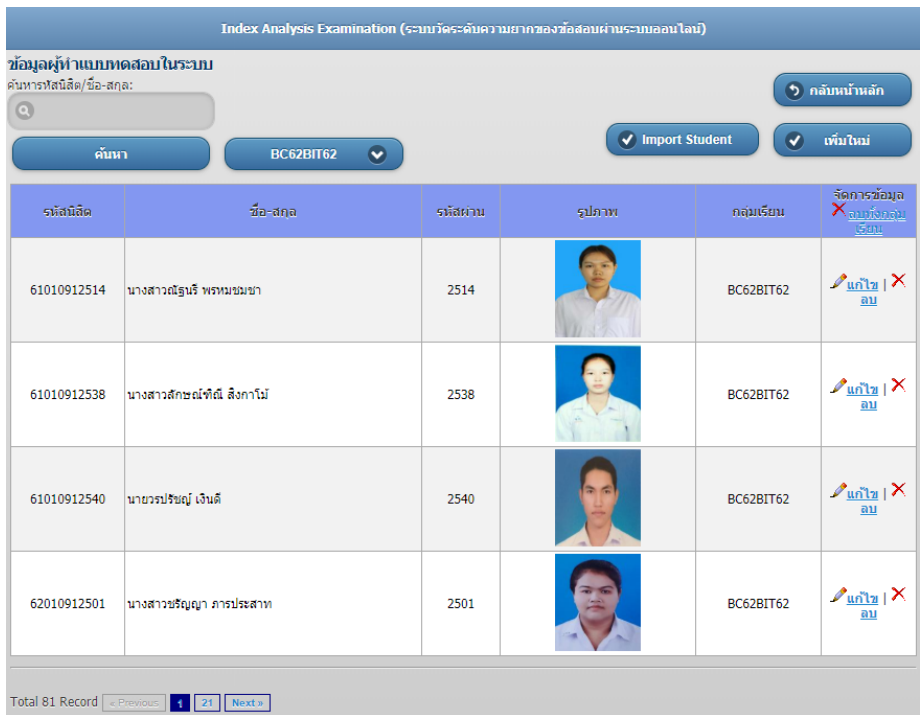

Fig. 6: The snapshot of students' profile (https://www.mse-exam.net/manage_std.php)

\begin{tabular}{|c|c|c|c|c|c|}
\hline \multicolumn{6}{|c|}{ 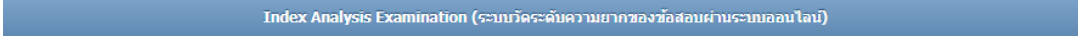 } \\
\hline \multirow{2}{*}{\multicolumn{2}{|c|}{$\begin{array}{l}\text { ข้อมูลประเภทแบบทดสอบ } \\
\text { คันหาชื่อแบบทดสอบ: } \\
\text { (a) }\end{array}$}} & & & & \multirow{2}{*}{ (5) กลับหน้าหลัก } \\
\hline & & & & & \\
\hline \multicolumn{2}{|c|}{ คันหา } & & & & ( เพินใหม่ \\
\hline รหัสแบบทดสอบ & & ชือแบบทดสอบ & $\begin{array}{l}\text { จำนวนตัว } \\
\text { เสื่วก(ปรัยง }\end{array}$ & จากานวนข้อสอบ & จัดการข้อมูล \\
\hline 1 & Quick1 & & 5 & 0 & แก้าข $\mid X_{\underline{a u}}$ \\
\hline 2 & Quick2 & & 5 & 15 & $\mathcal{L}_{\text {แก้าข } \mid} \times \underline{\underline{\underline{a u}}}$ \\
\hline 4 & Midterm & & 5 & 0 & แก้าข $\mid X_{\text {aิ }}$ \\
\hline 7 & LAB1 & & 0 & 5 & $\rho_{\text {แก้ใข } \mid} X_{\underline{a u}}$ \\
\hline 29 & $\underline{\perp A B 22}$ & & 4 & 0 & $\Omega_{\text {แก้าขอ } \mid} X_{\underline{\underline{a u}}}$ \\
\hline 82 & $\angle A B B C$ & & 5 & 0 & $\gamma_{\text {แก้าข } \mid} X_{\text {ลบ }}$ \\
\hline 122 & บทที่ 1 จับเว & & 4 & 2 & $\delta_{\text {แก้าข } \mid} X_{\text {ํㅡ }}$ \\
\hline 167 & Intro Progr & & 4 & 12 & $\rho_{\text {แก้าข } \mid} \times$ \\
\hline
\end{tabular}

Fig. 7: The snapshot of exam types (https://www.mse-exam.net/manage_exam_type.php) 


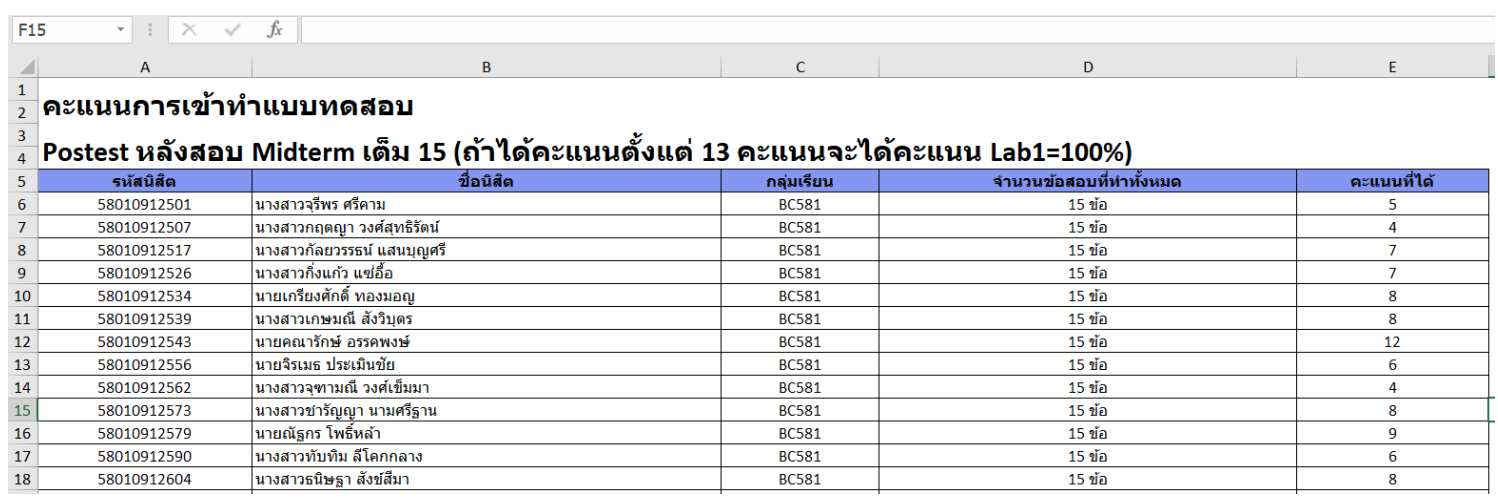

Fig. 8: The snapshot of spreadsheet export file

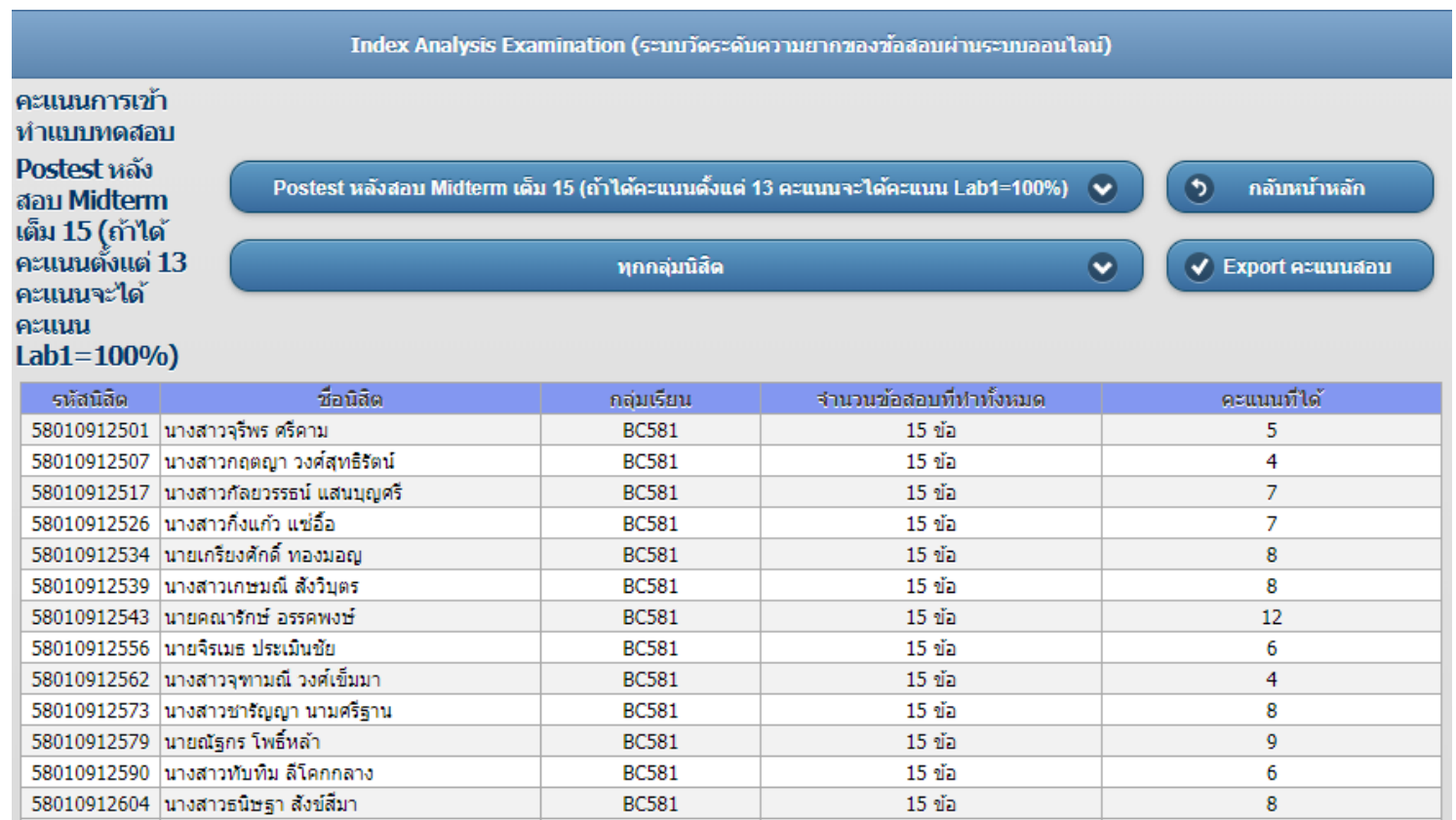

Fig. 9: The snapshot of score report (https://www.mse-exam.net/score_report.php)
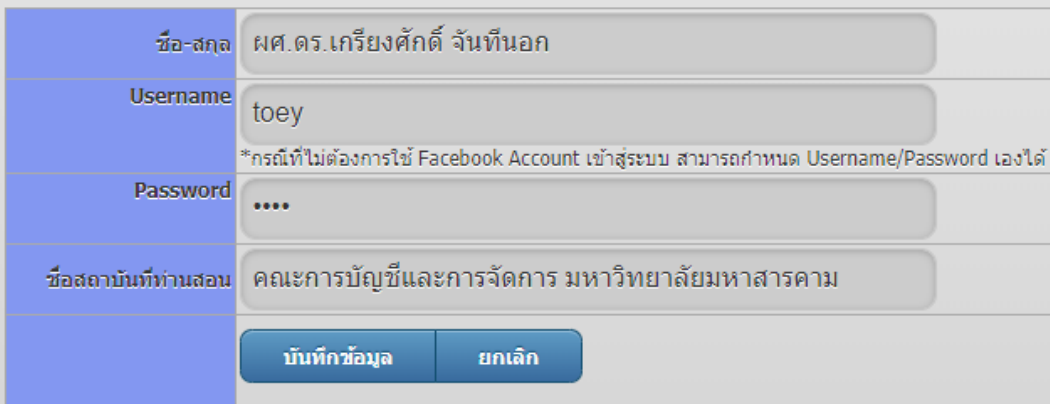

Fig. 10: The snapshot of profile edition page (https://www.mse-exam.net/add_edit_teacher.php) 
The key function of the IAE system is the equation for the item difficulty index calculation as illustrated in Equation 1:

$P=R / N$

$P=$ Item difficulty index

$R=$ Number of correct answers in each item

$N=$ Total number of testing

This equation is able to get the item difficulty indexes with different interpretations as follow in Table 1.

Table 1: Item difficulty index interpretation (Saiyot and Saiyot, 2000)

\begin{tabular}{ll}
\hline $\mathrm{P}$ & Implication \\
\hline $0.81-1.00$ & Very easy (should review or cut off) \\
$0.60-0.80$ & Quite easy \\
$0.40-0.59$ & Perfectly \\
$0.20-0.39$ & Quite difficult \\
$0.00-0.19$ & Very difficult (should review or cut off) \\
\hline
\end{tabular}

The Attribute of Use, Perceived Ease of Use, User's Satisfaction and Attribute of Use Perceived Ease of Use etc. should be written by the same order given in the next page also Attribute of use is repeated twice.

Hypothesis 1: The user of IAE would show high satisfaction

Hypothesis 2: The user in difference of (a) gender, (b) educational level and (c) audient type would show no difference in level of Perceived Usefulness

Hypothesis 3: The user in difference of (a) gender, (b) educational level and (c) audience type would show no difference in level of Perceived Ease of Use

Hypothesis 4: The user in difference of (a) gender, (b) educational level and (c) audience type would show no difference in level of User's Satisfaction

Hypothesis 5: The user in difference of (a) gender, (b) educational level and (c) audience type would show no difference in level of Attribute of Use

Figure 3 to 10 show snapshots of the system.

\section{Materials and Methods}

This research mainly developed the system in two parts. The first part was to implement the item analysis examination system on a domain name www.mseexam.net. Based on the cloud computing service, PHP language was used to develop the system and MySQL was used as a database to store the data. The teachers were allowed to import the examination and to customize the types of the exam themselves. The second part was using the questionnaire to assess the use of the IAE system in which the 5-point Likert scale was applied for each set of questionnaires. The scales were classified as follows: (1) Strongly disagree, (2) Disagree, (3) Neutral, (4) Agree, (5) Strongly agree (Abu-Dalbouh, 2013).

\section{Perceived Usefulness}

It was defined as the degree to which the professional instructor believes that the education industry should be improved by the proposed item analysis examination system. There were 4 items of the Perceived Usefulness assessment as shown in Table 2.

\section{Perceived Ease of Use}

It refers to the degree to which it is believed to use the proposed item analysis examination system in order to improve the student's learning quality in the educational institutes. The Perceived Ease of Use measurement was based on 5 items as shown in Table 2.

\section{User's Satisfaction}

It could be experienced in various situations related to the system. Actually, it was a highly personal assessment that could be greatly affected by the user's expectation. In this regard, there were 4 items of assessment as shown in Table 2.

Based on the literature review, the rating scores of the user's satisfaction was classified into five levels (Collins et al., 2000):

Mean Score between 4.51-5.00 = Highest

Mean Score between 3.51-4.50 = High

Mean Score between 2.51-3.50 = Neutral

Mean Score between 1.51-2.50 = Low

Mean Score between 1.00-1.50 = Lowest

\section{Attribute of Use}

It was referred to human interaction when the proposed item analysis examination system was used to fulfill the gap between human expectation and the system. This is being solved by introducing the human issues into the interactive design of the item analysis examination system and by devising practical techniques to observe human behaviors and performance. The measurement of Attribute of Use was focused on 5 items as shown in Table 2 .

Sampling Technique: Population was processed from the users registered into the IAE system and the sample was later randomized for all members. The respondents were the volunteer usually involved with the IAE system (Snedecor and Cochran, 1989). 
Table 2: Measured items

\begin{tabular}{|c|c|c|c|}
\hline Construct & Measured Items & $\begin{array}{l}\text { Factor } \\
\text { Loading }\end{array}$ & $\begin{array}{l}\text { Cronbach' } \\
\text { Alpha }\end{array}$ \\
\hline Perceived & PUF1: Item Analysis Examination (IAE) system enables the student's exam score history. & 0.794 & 0.860 \\
\hline \multirow[t]{3}{*}{ Usefulness } & PUF2: Item Analysis Examination (IAE) system helps increase the speed of the exam result display. & 0.815 & \\
\hline & PUF3: Item Analysis Examination (IAE) system will improve the student's tracking and monitor & 0.870 & \\
\hline & PUF4: Item Analysis Examination (IAE) system optimizes exam efficiency. & 0.878 & \\
\hline Perceived & PEU1 ${ }^{* 4}$ : Learning to operate Item Analysis Examination (IAE) system world be easy for me. & 0.831 & 0.917 \\
\hline \multirow[t]{4}{*}{ Ease of Use } & PEU2: I would find it easy to get Item Analysis Examination (IAE) system to do what I want it to do. & 0.871 & \\
\hline & $\begin{array}{l}\text { PEU3: The user's interaction with Item Analysis Examination (IAE) system would be understandable } \\
\text { and friendly. }\end{array}$ & 0.869 & \\
\hline & PEU4: I would find Item Analysis Examination (IAE) system flexible to interact with. & 0.891 & \\
\hline & PEU5: It would be easy for me to become skillful at using Item Analysis Examination (IAE) system. & 0.874 & \\
\hline User's & USF1: I am completely satisfied with using Item Analysis Examination (IAE) system. & 0.869 & 0.890 \\
\hline \multirow[t]{3}{*}{ Satisfaction } & USF2: I feel very confident in using Item Analysis Examination (IAE) system & 0.892 & \\
\hline & USF3: I can accomplish the task quickly using this IAE system. & 0.876 & \\
\hline & $\begin{array}{l}\text { USF4: I believe that using Item Analysis Examination (IAE) system will decrease the errors and save } \\
\text { my time. }\end{array}$ & 0.835 & \\
\hline \multirow{5}{*}{$\begin{array}{l}\text { Attribute } \\
\text { of Use }\end{array}$} & AOU1: It is easy to interact with Item Analysis Examination (IAE) system. & 0.811 & 0.909 \\
\hline & AOU2: The procedure through Item Analysis Examination (IAE) system is clearly explained. & 0.877 & \\
\hline & $\begin{array}{l}\text { AOU3: I found that various functions in this Item Analysis Examination (IAE) system are } \\
\text { useful and communicative. }\end{array}$ & 0.869 & \\
\hline & $\begin{array}{l}\text { AOU4: I found that various functions in the Item Analysis Examination (IAE) system are } \\
\text { well integrated. }\end{array}$ & 0.870 & \\
\hline & AOU5: I think I desire to use this Item Analysis Examination (IAE) system always. & 0.859 & \\
\hline
\end{tabular}

Data Analysis Techniques: The data analysis was mainly conducted in 3 manners: (1) Item Validity Measurement to define the Goodness of Data; (2) Descriptive Statistic to find gender the percentage of gender, age, audience type and the number of users in IAE system; and (3) the research hypothesis confirmation.

Variable Measurement: The questionnaire approach was used to evaluate the IAE system so it contained 3 sections: (i) Personal Demographic Information, (ii) Rating Scale on Perceived Usefulness, Perceived Ease of Use, User's Satisfaction, Perceived Ease of Use and Attribute of Use-these two sections provided different sets of question items to evaluate the effectiveness of the proposed IAE system from the intended users; and (iii) the open-ended questions for any either comment or suggestion to improve the system in the future.

Item reliability scale: Cronbach's alpha is a popular method to measure reliability. Especially, in the quantitative research. The reliability of a score is to summarize the information of several items in the questionnaires (Christmann and Van Aelst, 2006; Thoumrungroje, 2017). To evaluate the consistency within a collection of multiple items, if all items measure the same concept, then it is highly correlated. The value of Cronbach's alpha is between zero and one, of which 0.6 and above indicates acceptable reliability (Nunnally and Bernstein, 1994).

Moreover, the content analysis was the first considered process to judgmentally verify the quality of the research instrument. Three experts were proofreading each item question and essence of the scale representing the constructs of the instrument. The constructs' validity was referred to as the scale that correctly measures what it was supposed to measure. Besides, the factor loading analysis was utilized to examine and assess the underlying relationships amongst a large number of question items and to determine whether they could be reduced to a smaller set of factors (Ussahawanitchakit, 2012). All factor loadings were greater than 0.40 cut-off which were statistically significant (Nunnally and Bernstein, 1994); meanwhile, the reliability scale was estimated with Cronbach's Alpha Coefficient in which the suggested score with sufficient internal consistency would be greater than 0.60 (Malhotra, 2004; Nunnally and Bernstein, 1994). The validated result of both factor loadings and Cronbach's alpha for multiple-item scales were presented in Table 2.

\section{Results and Discussion}

The study result was divided into 2 parts. Firstly, the IAE system development basically starts with the system analysis and design following the flowchart and dataflow diagram where the common requirement was the item difficulty analysis. A number of question items can be imported as the spreadsheet format in which the teachers were able to detect any of the students' learning growth The registration revealed there were 284 teachers and 7,323 students accessed into the IAE system; Secondly, the six months after launching the website "mseexam.net", the IAE system was tested for its Perceived Usefulness. Perceived Ease of Use, Perceived Ease of use. User's Satisfaction and Attribute of Use, whereas the question items were mostly adapted from the previous research by Abu-Dalbouh et al. (2019). Furthermore, the researcher offered Google Analytics to track all users as shown in Fig. 11. 
The IAE system was evaluated by 266 respondents and the result showed that the system was a promising tool with high effectiveness for all educational institutes. All variables were typically measured using 5-points Likert scale: (1) Strongly disagree, (2) Disagree, (3) Nature, (4) Agree and (5) Strongly agree; on the other hands, User's Satisfaction was assessed with another 5points Likert scale: (1) Lowest satisfaction, (2) Low satisfaction, (3) Neutral satisfaction, (4) High satisfaction and (5) Highest satisfaction.

The descriptive statistics was showed as in Table 3. Item 1: Item Analysis Examination (IAE) system helps increase the speed of exam result display was rated with, the highest mean of 4.526 and Standard Deviation of 0.633; the statistics of Item 1 was shown in Fig. 12. Then Item 2: I believe that using Item Analysis Examination (IAE) system would reduce the errors and save my time, was rated secondly with the highest mean of 4.387 and Standard Deviation of 0.682; the statistics of Item 2 was presented in Fig. 13. Finally, Item 3: It is easy to interact with Item Analysis Examination (IAE) system, was rated thirdly with the highest mean of 4.376 and Standard Deviation of 0.674 . The statistics of Item 3 was illustrated in Fig. 14. Therefore, the user's satisfaction in Table 3 indicated that the mean score was higher than 3.50, thus, Hypothesis 1 was confirmed. Accordance with the empirical research result found by Abu-Dalbouh (2013) that high levels of user satisfaction are important to mobile tracking on patient progress system. The system was useful for physicians and nurses in healthcare industry.

Table 4 presented the output of the t-test analysis which was used to affirm Hypothesis 2a, 3a, 4a and 5a to make sure if there was any statistically significant difference in the mean score amongst the groups with different genders. The result indicated that the mean score was different between the male and female groups. In addition, there was the statistical significance in the IAE system in terms of Perceived Usefulness (PUF, $\mathrm{p}=$ 0.005), Perceived Ease of Use (PEU, $p=0.001$ ), User's Satisfaction (USF, $\mathrm{p}=0.001$ ) and Attribute of Use (AOU, p = 0.019). Therefore, Hypothesis 2a, 3a, 4a and 5a were proved to be wrong. Although this empirical research did not correctly follow the assumption, it provides another distinctive insight for the Thai audience, particularly for Thai males who are naturally more challenging than the females to use new technology and have more options to try. Although, the variable testing is the same study with Abu-Dalbouh et al. (2019), they are no study in t-test analysis between gender groups. The study only focused on rating evaluate in electronic health records in four aspectsPerceived Usefulness, Perceived Ease of Use, User's Satisfaction and Attribute of Use.
However, this research result was promoted by Venkatesh et al. (2012). They suggested that men and women typically take on different social roles and exhibit different role behaviors. Especially, men are likely to be competitive and make decisions based on selective information and heuristics, while women tend to be more inter-dependent, cooperative and consider more details (Deaux and Kite, 1987). As a result, Perceived Usefulness, Perceived Ease of Use, User's Satisfaction and Attribute of Use are differences in opinions between male and female.

Table 5 gives the detail of ANOVA analysis for all the categories for those with no statistically significant difference in their educational levels. Actually, the sample group were in the three educational levels including Ph.D., Master and Bachelor degrees and knew nothing about the IAE system regarding Perceived Usefulness (PUF, $\mathrm{p}=0.565$ ), Perceived Ease of Use (PEU, $\mathrm{p}=0.322$ ), User's Satisfaction (USF, $\mathrm{p}=0.629)$ and Attribute of Use (AOU, p = 0.710). As a result, Hypothesis 2b, 3b, 4b and 5b were confirmed.

Table 6 provided the detail for all the groups where there were none of the statistically significant differences in audience type proportion. There were two audience types between students and teachers showing no difference in their attitude toward the IAE system in terms of Perceived Usefulness (PUF, $\mathrm{p}=0.187$ ), Perceived Ease of Use (PEU, $p=0.197$ ), User Satisfaction (USF, $p=0.215$ ) and Attribute of Use (AOU, p = 0.261). Consequently, Hypothesis 2c, 3c, $4 c$ and $5 c$ were confirmed. In addition, this result indicated that both students and teachers showed a positive perspective toward the use of the IAE system.

Table 3: Descriptive statistical analysis $(\mathrm{N}=266)$

\begin{tabular}{lcc}
\hline Items & Mean & S.D. \\
\hline Perceived usefulness & 4.331 & \\
PUF1 & 4.526 & 0.675 \\
PUF2 & & 0.633 \\
PUF3 & 4.342 & 0.689 \\
PUF4 & 4.331 & 0.653 \\
Perceived ease of use & & \\
PEU1 & 4.357 & 0.676 \\
PEU2 & 4.331 & 0.675 \\
PEU3 & 4.289 & 0.652 \\
PEU4 & 4.305 & 0.674 \\
PEU5 & 4.323 & 0.627 \\
User's satisfaction & & \\
USF1 & 4.331 & 0.647 \\
USF2 & 4.274 & 0.635 \\
USF3 & 4.229 & 0.670 \\
USF4 & & 0.682 \\
Attribute of use & 4.387 & \\
AOU1 & & 0.674 \\
AOU2 & 4.376 & 0.662 \\
AOU3 & 4.237 & 0.657 \\
AOU4 & 4.256 & 0.622 \\
AOU5 & 4.376 & 0.660 \\
\hline
\end{tabular}


Table 4: t-test analysis-gender proportion

\begin{tabular}{|c|c|c|c|c|c|c|}
\hline \multirow[b]{2}{*}{ Construct } & \multicolumn{2}{|c|}{ Male $(\mathrm{N}=30)$} & \multicolumn{2}{|c|}{ Female $(\mathrm{N}=236)$} & \multirow[b]{2}{*}{$\mathrm{t}$} & \multirow[b]{2}{*}{ Sig. } \\
\hline & Mean & S.D. & Mean & S.D. & & \\
\hline PUF (H2a) & 4.617 & 0.444 & 4.353 & 0.563 & 2.967 & $0.005 * *$ \\
\hline PEU (H3a) & 4.613 & 0.461 & 4.284 & 0.576 & 3.577 & $0.001 * *$ \\
\hline USF (H4a) & 4.625 & 0.458 & 4.265 & 0.572 & 3.313 & $0.001 * *$ \\
\hline AOU (H5a) & 4.533 & 0.523 & 4.280 & 0.561 & 2.351 & $0.019^{*}$ \\
\hline
\end{tabular}

Note: * The mean difference was significant at the 0.05 level. and ** The mean difference was significant at the 0.01 level

Table 5: ANOVA analysis-Educational level (Ph.D., Master, Bachelor Degree)

\begin{tabular}{lllllll}
\hline Construct & & Sum of squares & df & Mean square & F & Sig. \\
\hline PUF (H2b) & Between Groups & 0.355 & 2 & 0.178 & 0.572 & 0.565 \\
& Within Groups & 81.661 & 263 & 0.310 & \\
& Total & 82.016 & 265 & & 0.138 \\
PEU (H3b) & Between Groups & 0.746 & 2 & 0.373 & 0.322 \\
& Within Groups & 86.276 & 263 & 0.328 & 0.465 \\
& Total & 87.022 & 265 & & 0.629 \\
USF (H4b) & Between Groups & 0.305 & 2 & 0.152 & 0.328 \\
& Within Groups & 86.190 & 263 & 0.343 & 0.710 \\
& Total & 86.495 & 265 & & \\
& Between Groups & 0.217 & 2 & 0.108 & & \\
& Within Groups & 83.305 & 263 & 0.317 & & \\
& Total & 83.522 & 265 & & \\
\hline
\end{tabular}

Note: $*$ The mean difference is significant at the 0.05 level. and $* *$ The mean difference is significant at the 0.01 level

Table 6: t-test analysis-Audient type

\begin{tabular}{|c|c|c|c|c|c|c|}
\hline \multirow[b]{2}{*}{ Construct } & \multicolumn{2}{|c|}{ Student $(\mathrm{N}=251)$} & \multicolumn{2}{|c|}{ Teacher $(\mathrm{N}=15)$} & \multirow[b]{2}{*}{$\mathrm{t}$} & \multirow[b]{2}{*}{ Sig } \\
\hline & Mean & S.D. & Mean & S.D. & & \\
\hline PUF (H2c) & 4.372 & 0.555 & 4.567 & 0.563 & -1.322 & 0.187 \\
\hline PEU (H3c) & 4.310 & 0.566 & 4.507 & 0.679 & -1.293 & 0.197 \\
\hline $\mathrm{USF}(\mathrm{H} 4 \mathrm{c})$ & 4.295 & 0.644 & 4.483 & 0.644 & -1.243 & 0.215 \\
\hline AOU (H5c) & 4.298 & 0.559 & 4.467 & 0.603 & -1.125 & 0.261 \\
\hline
\end{tabular}

Note: * The mean difference is significant at the 0.05 level. and ** The mean difference is significant at the 0.01 level

Apparently, the empirical result indicated that information technology has an important role in our lives in several extents, due to its powerful variety that completely changes the life-style of people and how we act and interact with one another as well as the educational system around the world.

Based on the research result, the main constructs represented that the proposed IAE system makes it possible to put the examination server base on the cloud computing service as the audiences were highly satisfied with Perceived Usefulness, Perceived Ease of Use, User's Satisfaction and Attribute of Use. Furthermore, the IAE system was purposively built to share not only the service within a university but also open access for other universities or schools in the digital era.
Recently, the online examination has been applied to an e-learning system. Especially during the outbreak of Coronavirus Disease 2019 (COVID-19), this pandemic is widely providing a negative effect to all people in the world while the people's daily lifestyle is changing and needs to seriously follow the government's order; for example, people are disallowed to work at the office but they are allowed to work from home using the internet. Thus, following basic principles can helpfully keep students, teachers and staffs safe and help stop the spread of this disease. At this point, the online learning course and examination are usefully implemented as our world has been digitally transformed by technology so that most people can simply get access to various platforms of technology e.g., smartphones, tablets or any electronic devices to search information on web sites. 


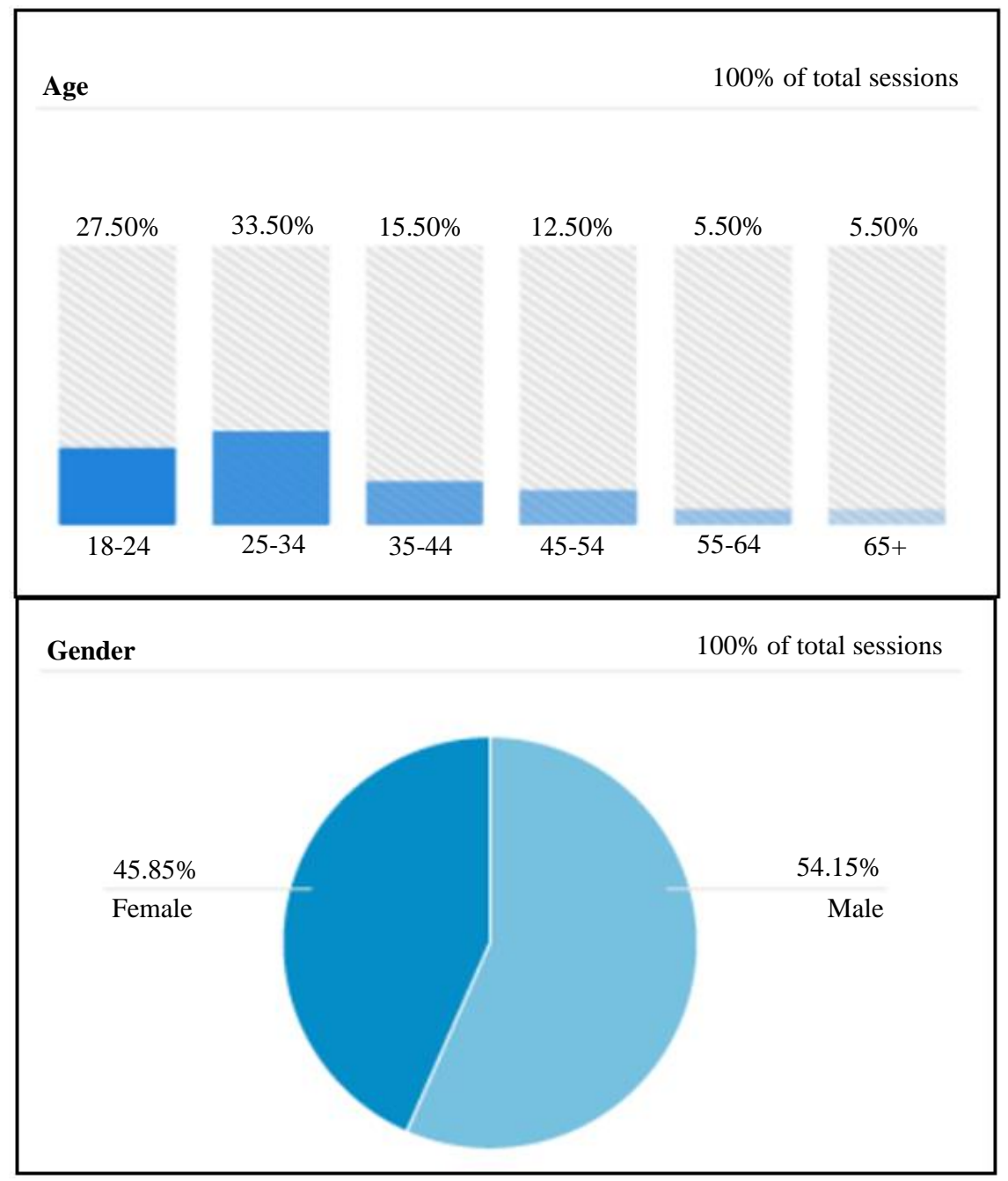

Fig. 11: A total sessions of the IAE system users with difference in age and gender from google analytics

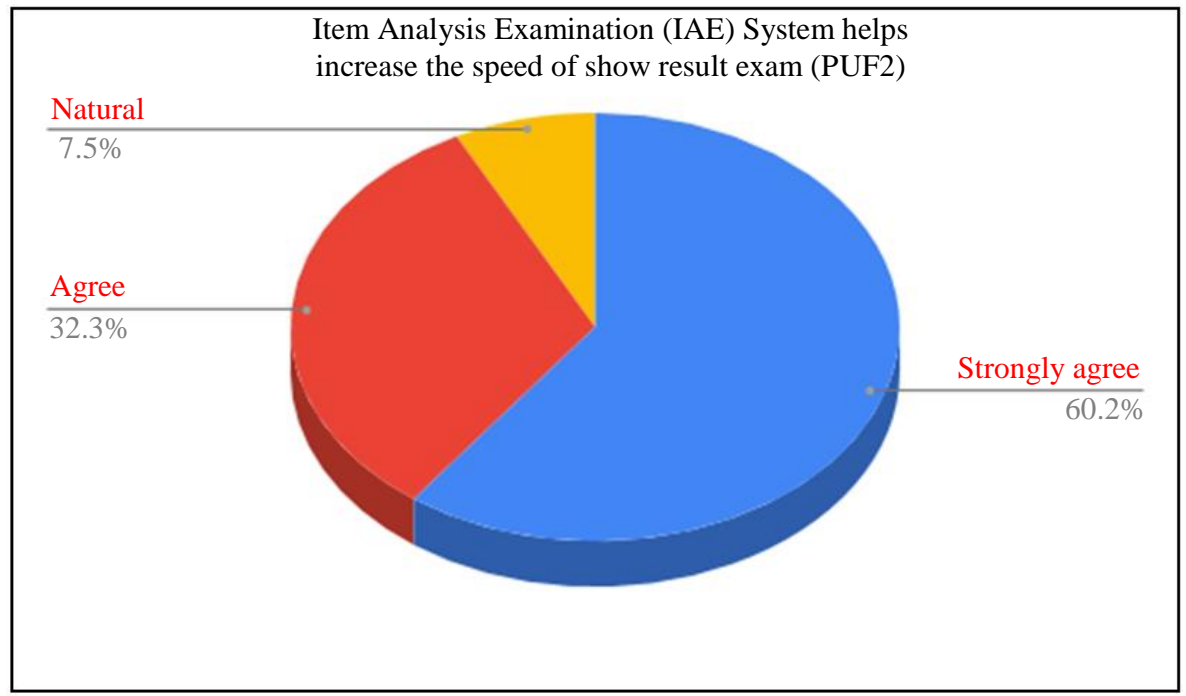

Fig. 12: Item 1- Highest statistics (shows that $60.2 \%$ of the respondents strongly agreed and $32.3 \%$ agreed on of Perceived Ease of Use) 


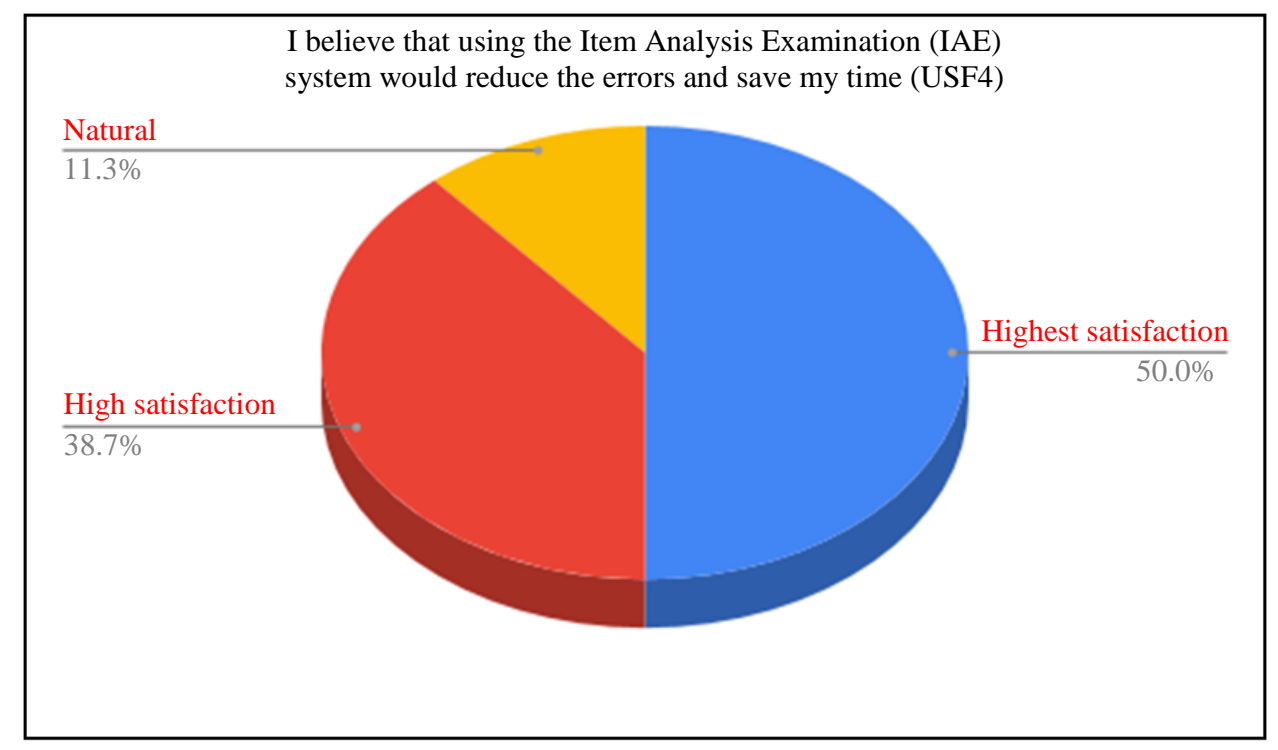

Fig. 13: Item 2 - High statistics (shows that $50 \%$ of the respondent rated at the highest level and $38.7 \%$ of the user's satisfaction was rated at a high level)

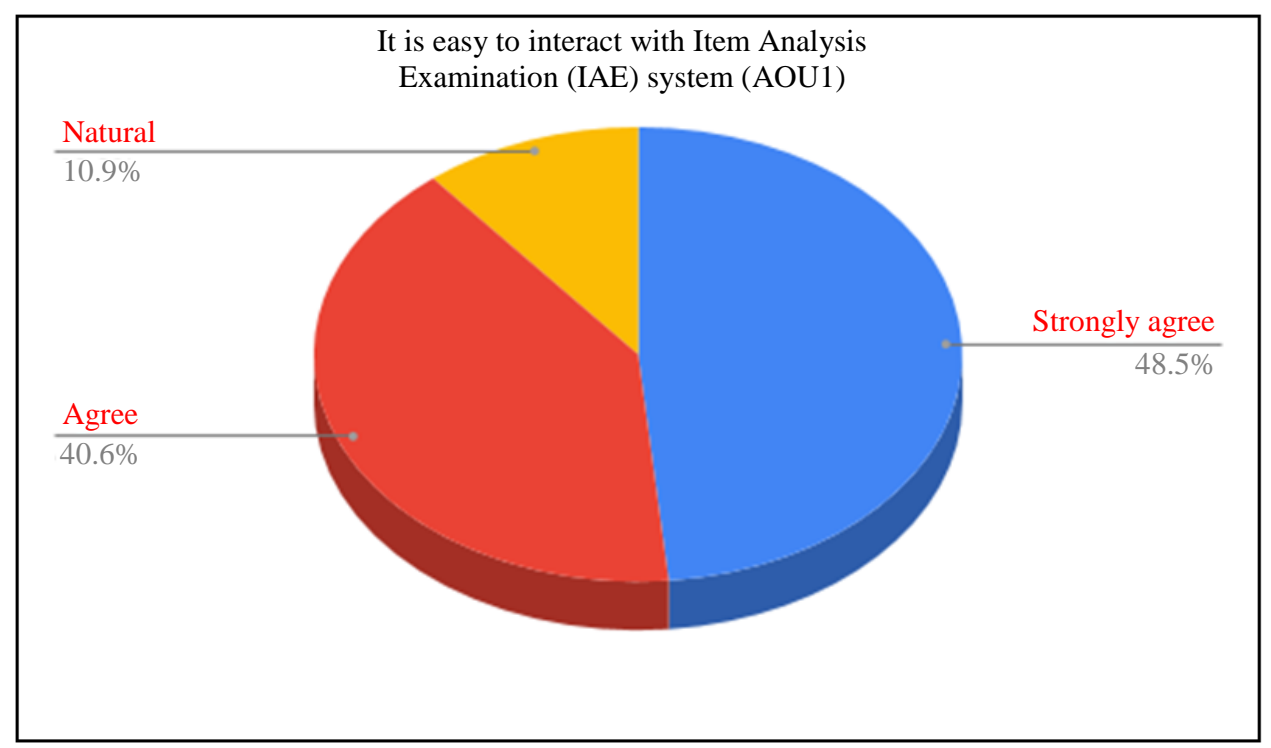

Fig. 14: Item 3- High statistics (shows that $48.5 \%$ of the respondent strongly agreed and $40.6 \%$ agreed on an easy interaction with the IAE system

\section{Contributions and Limitations}

The IAE system provides the openly accessible service for educational purposes that allows not only Thailand but also other countries to freely register and use it. The contribution of the research is to facilitate the teachers to effectively analyze the student's learning background and to design the appropriate teaching approach before organizing teaching and learning activities. Moreover, the teachers can use this IAE system as a tool to measure and evaluate the students skills, processes, capabilities and potential of via a realtime assessment on a mobile phone or computer notebook in which the score can be shown and analyzed immediately by not wasting lots of paper or printing (Paperless). This benefit helps reduce unnecessary use of resources; for instance, reduce the deforestation rate or the electricity consumption in the paper mills. This is cost-saving for an organization so they can save money for other useful activities rather than paper purchasing.

In term of saving the budget from paper purchase based on the list of 178 higher education institutions in 
Thailand (https://en.wikipedia.org/wiki/list of higher education institutions in Thailand). it can be assumed that within one fiscal year, approximately 100,000 THB will be spent on purchasing the materials for student's examination, measurement and evaluation for totally 178 institutes and this is equivalent to saving an annual budget of $17,800,000$ baht. The fact is that if this amount of money was used on developing other infrastructures, it would surely gain greater benefits and economic values for the country.

However, in the case of subjective examination (Open-End answer), the IAE system can display all answers at the same time; meanwhile, the teachers are allowed to read through the answers so they can give each student fair scores; this helps reduce possible errors and bias. Above all, this IAE system consistently responds to the government's policy "Thailand 4.0" in which the instructional tools should be developed as the digital platforms and easy for use.

Nowadays, the IAE system is available online at www.mse-exam.net. Although the system is globally accessible at schools, some features need to be revised for better performance of service. Hence, this project aims to provide the source code and database to run your own server. Although the IAE system is online at $24 / 7$, traffic jam may be occurred when there are a lot of users like teachers and students access the program at the same time. There is limitation of no more 300 students in each section.

Additionally, some suggestions were listed below:

- Developing the question items in the exam from the previous version for better testing in the next exam

- The difficulty index would display the item analysis only after the exam finished

- Designing the IAE system to be able to insert a photo into the question and answer

- Adding a section for choosing between the answer and open-ended answer which are integrated into one exam

- Adding a countdown timer feature e.g. schedule or calendar to start and stop the exam

- Adding an answer recheck button before the exam expiry time if there still have time before students submit the answer

\section{Conclusion}

We have done research to follow the objectives of the study. The objectives of this research are (1) To develop the difficulty index analysis software for multiple-choice examination via cloud computing service and (2) To assess the IAE system's Perceived Usefulness, Perceived Ease of Use, User's Satisfaction and Attribute of Use.

The first objective, the IAE system had developed and also available online at www.mse-exam.net. The researchers are willed to share and distribute the benefits from this study to other agencies who are interested in implementing the system free of charge. Also, an individual person can manage the system himself so it can greatly save a number of human resources and financial resources. More importantly, this IAE system is considered a part of building the sharing and learning society amongst the educational institutions in order to motivate the academic competitiveness so that each institution will be encouraged to actively produce quality graduates with knowledge and competency in accordance with the goals of Thai society and to create prosperity for the nation.

The second objective, we assessed the IAE system's Perceived Usefulness, Perceived Ease of Use, User's Satisfaction and Attribute of Use. There are five hypotheses that empirical proved from teachers and students which used the IAE system. The result concluded that the users of IAE would show high satisfaction-all mean score more than 3.5 point. Surprisingly, the mean score was different between men and women. Although, there was the statistical significance in the IAE system in terms of Perceived Usefulness, Perceived Ease of Use, User's Satisfaction and Attribute of Use, but the result can explain with different social role and exhibit role behaviors (Venkatesh et al., 2012; Deaux and Kite, 1987). In group of educational level was test by ANOVA analysis. The result was confirm with no statistcially signifigcant in Ph.D., Master and Bachelor degree. Moreover, there were two audience types between students and teachers showing no difference in their attitude toward the IAE system in terms of Perceived Usefulness, Perceived Ease of Use, User Satisfaction and Attribute of Use. Consequently, this result implies that both students and teachers showed a positive perspective toward the use of the IAE system.

\section{Acknowledgment}

We would like to thank Mahasarakham Business School, Mahasarakham University, which is financially supported for research and developing the IAE system.

\section{Author's Contributions}

Kriangsak Chanthinok: Inventing the idea, designed both the IAE system and the research plan. Writing the manuscript, designing the data dictionary, data flow diagram, database design and coding the program.

Palan Jantarajaturapath: Contributing to the literature review with the related fields. Designing the study, developing the methodology, collecting the data, performing the data analysis and approving the final manuscript. 


\section{Ethics}

This article is originally licensed and still contains the unpublished sections in another journal. The corresponding author confirms that all of the other authors have read and approved the manuscript and no ethical issues concerned.

\section{References}

Abu-Dalbouh, H.M., 2013. A questionnaire approach based on the technology acceptance model for mobile tracking on patient progress applications. J. Comput. Sci., 9: 763-770.

DOI: $10.3844 /$ jcssp.2013.763.770

Abu-Dalbouh, H.M., M. Al-Matrouk, N. Al-Zwaid and A. Al-Handi, 2019. Proposal of a standardized electronic health record for Kingdom of Saudi Arabia. J. Comput. Sci., 15: 566-581.

DOI: 10.3844/JCSSP.2019.566.581

Aye, M.M. and M.M.T. Thwin, 2008. Mobile agent based online examination system. Proceedings of the 5th International Conference on Electrical Engineering/Electronics, Computer, Telecommunications and Information Technology, May 14-17, IEEE Xplore Press, Krabi, Thailand, pp: 193-196. DOI: 10.1109/ECTICON.2008.4600405

Bhardwaj, S., L. Jain and S. Jain, 2010. Cloud computing: A study of Infrastructure As A Service (IAAS). Int. J. Eng. Inform. Technol., 2: 60-63. DOI: $10.1007 / \mathrm{S} 11738-015-1899-3$

Bhoomin Ton-Oud, 2017. The development of multiple choices answering paper checking systems by image processing method. Sci. Technol. Nakhon Sawan Rajabhat Univ. J., 9: 113-126.

Chinnasri, W. and S. Wasukree, 2016. A development of web application for item analysis on objective test. VRU Res. Dev. J. Sci. Technol., 10: 1-17.

Christmann, A. and S. Van Aelst, 2006. Robust estimation of Cronbach's alpha. J. Multivariate Anal., 97: 1660-1674.

DOI: 10.1016/J.JMVA.2005.05.012

Collins, W.C., N.S. Raju and J.E. Edwards, 2000. Assessing differential functioning in a satisfaction scale. J. Applied Psychol. US: Am. Psychol. Assoc.
Deaux, K. and M.E. Kite, 1987. Thinking About Gender. In: Analyzing Gender: A Handbook of Social Science Research, Hess, B.B. and M.M. Ferree (Eds.), Sage Publications, Inc, p: 92-117.

Höfer, C.N. and G. Karagiannis, 2011. Cloud computing services: Taxonomy and comparison. J. Int. Services Applic., 2: 81-94. DOI: 10.1007/S13174-011-0027-X

Malhotra, N.K., 2004. Marketing Research: An Applied Orientation. 4th Edn., Pearson/Prentice Hall, ISBN-10: 0130337161, pp: 713.

Nunnally, J.C. and I.H. Bernstein, 1994. Psychometric Theory. 3rd Edn., McGraw-Hill, ISBN-10: 007047849X, pp: 752.

Nuthong, S., S. Witosurapot and B. Nuthong, 2019. Automatic quiz generation mechanism for multiple choices question by applying ontological data. Ratjmangala Univ. Technol. Krungthep Res. J., 13: 156-166.

Saiyot, L. and O. Saiyot, 2000. Educational Tests and Measurements. 1st Edn., Creative Media Partners, LLC, ISBN-10: 0469232501, pp: 330.

Snedecor, G.W., W.G. Cochran, 1989. Statistical Methods. 8th Edn., Academic Press, ISBN-10: 0080961037, pp: 824.

Sungnul, S., C. Baitiang and S. Ratanapun, 2011. Software development for subjective test analysis. J. Kmutnb, 21: 627-635.

Thoumrungroje, A., 2017. International Business Research: Principles and Applications. 1st Edn., Triple Education Co., Ltd. Bangkok, Thailand.

Ussahawanitchakit, P., 2012. Knowledge acquisition, technology acceptance, information richness and competitive advantage of e-commerce businesses in Thailand. Int. J. Bus. Strategy, 12: 56-65.

Venkatesh, V., J. Thong and X. Xu, 2012. Consumer acceptance and use of information technology: Extending the unified theory of acceptance and use of technology. MIS Quarterly, 36: 157-178. DOI: $10.2307 / 41410412$

Zhenming, Y., Z. Liang and Z. Guohua, 2003. A novel web-based online examination system for computer science education. Proceedings of the Frontiers in Education Conference, Nov. 5-8, IEEE Xplore Press, Westminster, CO, USA, pp: S3F7-S3F10. DOI: 10.1109/FIE.2003.1265999 